\title{
PERSPECTIVE
}

\section{Ganglion cell death in glaucoma: what do we really know?}

\author{
Neville N Osborne, John P M Wood, Glyn Chidlow, Ji-Hong Bae, José Melena, Mark S Nash
}

\section{What are the apparent characteristics of ganglion cells in glaucoma?}

Glaucomatous optic neuropathy is a chronic process which progresses over many years. Data derived from clinical observations and from animal experiments suggest that the axons of the optic nerve and the retinal ganglion cell somata do not die at the same time but that death can vary between months and many years. ${ }^{12}$ Glaucoma patients have characteristic fields of visual loss which enlarge as the disease progresses. Thus, glaucomatous optic neuropathy may not be a chronic degeneration of the whole of the optic nerve and ganglion cell somata but rather a series of acute losses of individual, or groups of, ganglion cells. It seems therefore reasonable to assume that when a patient is diagnosed initially as having glaucoma, only some ganglion cells are dead, whereas others may range from being "unhealthy" to being "slightly sick" while others are "perfectly normal". It seems also reasonable to argue that if a neuroprotectant (a substance which reaches the retina to elicit an effect: Table 1) can be applied at some stage before blindness occurs it could be of benefit to the glaucoma patient by either "slowing down" the death process of neurons that has already been initiated to die or perhaps by preventing the initiation of death signals to perfectly healthy ganglion cells. This argument can be made despite the lack of success in the use of neuroprotectants for a variety of other diseases (stroke, epilepsy, Parkinson's disease, AIDS dementia) where neuronal death is a characteristic. ${ }^{13}$ It is the apparent nature of ganglion cell death in glaucoma, very slow and variable, that makes it more likely that the use of neuroprotectants could be successful.

\section{Are certain retinal ganglion cells particularly susceptible?}

The evidence to suggest that certain ganglion cells in the retina are inherently more vulnerable than others is not overwhelming. For example, in tobacco/alcohol amblyopia which is a non-specific condition, similar to that which occurs in certain malnutritional states, ${ }^{4}$ there is a selective loss of the papillomacular bundle associated with a tempo-

Table 1 The term neuroprotection in glaucoma implies that the substance used to "protect" the ganglion cells reaches the retina ("direct

neuroprotection") to have an effect. In contrast, "indirect neuroprotection" of ganglion cells will occur when a risk factor, such as raised IOP, is corrected

\begin{tabular}{|c|c|}
\hline $\begin{array}{l}\text { Possible ways for " direct } \\
\text { neuroprotection" of ganglion cells }\end{array}$ & $\begin{array}{l}\text { Possible ways for "indirect } \\
\text { neuroprotection" of ganglion cells }\end{array}$ \\
\hline $\begin{array}{l}\text { - Neuroprotectant acts on ganglion } \\
\text { cell perikarya } \\
\text { - Neuroprotectant acts on retinal } \\
\text { and/or optic nerve glial cells } \\
\text { - Neuroprotectant acts on ganglion } \\
\text { cell axons } \\
\text { - Neuroprotectant acts on retinal } \\
\text { and/or optic nerve blood vessels } \\
\text { - Neuroprotectant acts on any of the } \\
\text { retinal neurons }\end{array}$ & $\begin{array}{l}\text { - Correct impaired elevated IOP } \\
\text { - Correct impaired decreased arterial } \\
\text { blood pressure } \\
\text { - Correct impaired deficit in } \\
\text { autoregulation } \\
\text { - Correct impaired local vasospasms } \\
\text { - Correct impaired systemic arterial } \\
\text { hypotension }\end{array}$ \\
\hline
\end{tabular}

ral pattern of ganglion cells. This corresponds to a subpopulation of smaller ganglion cells and their nerve fibres. ${ }^{5}$ Such a pathological pattern therefore suggests that the smaller ganglion cells are the most susceptible to malnutrition and vitamin deprivation. ${ }^{6}$

In contrast, in glaucoma (both human and monkeys), evidence favours the view that large ganglion cells of a type which is related to the magnocellular pathway are particularly susceptible. ${ }^{7-9}$ This is based primarily on histology where the diameter of axonal fibres and size of ganglion cell somata in both normal and glaucomatous eyes was measured. Some authors have questioned such data mainly because of the inherent difficulties of identifying ganglion cells in pathological tissues unequivocally. ${ }^{10}$

There is also a report on experimental monkey glaucoma where no apparent selective loss of ganglion cells of a particular cell size and type was found..$^{11}$ Moreover, in a recent study on a monkey model of glaucoma the individual ganglion cells were stained intracellularly to allow their dendrites and somata size to be analysed..$^{12}$ The authors concluded that in glaucoma an initial degeneration of the dendritic arbor of the ganglion cells occurs followed by a shrinkage of the cell somata. This suggests that the somata size of the same ganglion cell will appear, in pathological tissues of glaucoma patients, to be smaller than in a normal retina.

Since most of the evidence for suggesting that the larger ganglion cells are more susceptible than the smaller ganglion cells is based on histology, it is clear that this idea may be flawed. However, data from psychophysical tests on glaucoma patients, including tests of temporal contrast, motion, and scotopic sensitivity generally do not support the histological data for selective ganglion cell death since defects in both magnocellular and parvocellular pathways give similar results. ${ }^{13}{ }^{14}$ It should be pointed out that present histological data also suggest that some smaller ganglion cells are at least as susceptible as some of the largest ganglion cells in the first stages of glaucoma. Thus, it is a perception only that there is a preferential loss of larger diameter ganglion cells in the first stages of glaucoma and the evidence for such cells being part of the magnocellular pathway (as opposed to the parvocellular pathway) is inconclusive.

What initiates ganglion cell death in glaucoma? It is, in many respects, convenient to think of glaucoma as being a chronic disease in which all ganglion cells are insulted at about the same time (Fig 1A) but with variable death rates for individual cells (Table 2). ${ }^{15}$ Should different ganglion cell populations die by a series of acute insults $(\text { Fig } 1 \mathrm{~B})^{2}$ then we need to concern ourselves with issues such as why individual subsets of ganglion cells are initiated to die in the first place, what initiates subsequent subsets to die, and whether the process of death initiation for different subsets of ganglion cells varies. 

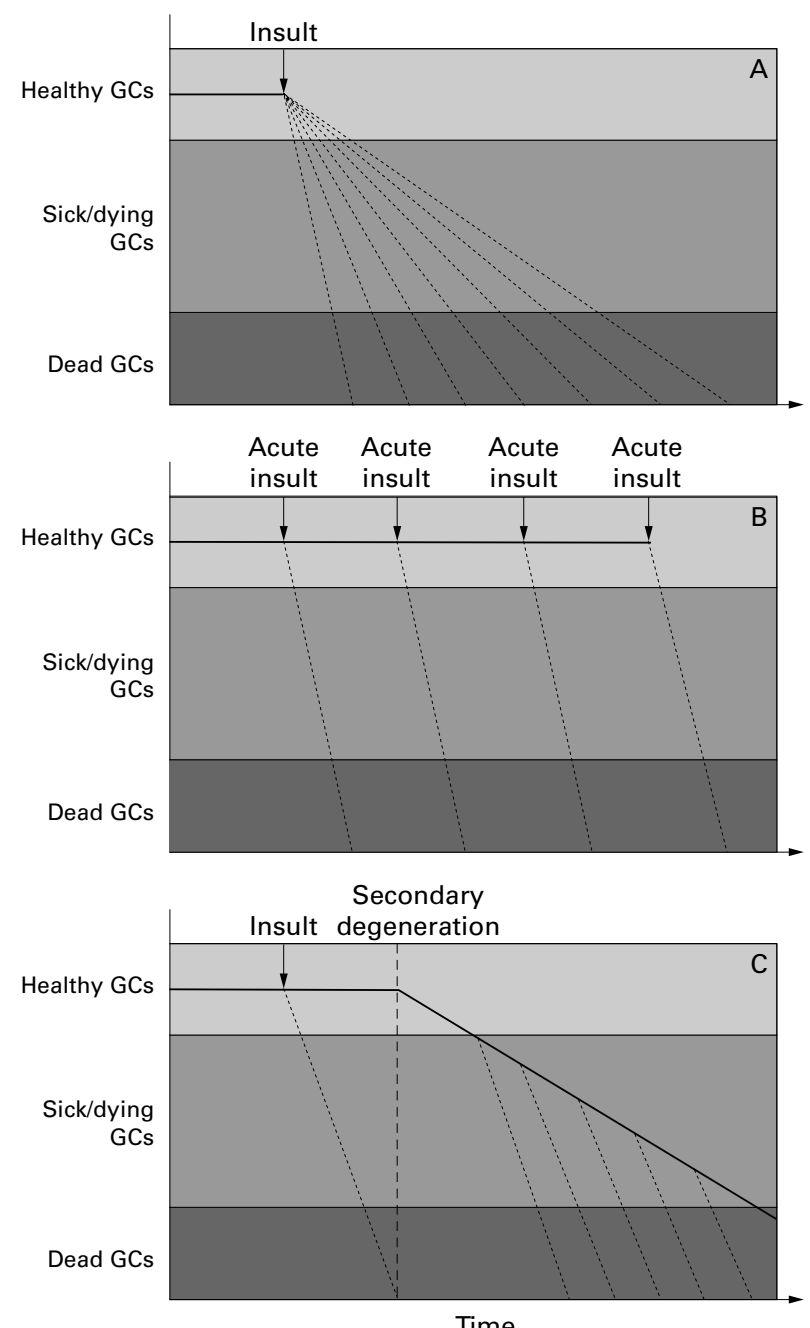

Figure 1 Three hypothetical views of how retinal ganglion cell death may occur in glaucoma. In $(A)$, all ganglion cells are initiated to die at more or less the same time but individual cells die at variable rates. In (B), a series of acute insults occurs at different periods and this leads to the death of subsets of ganglion cells all dying at similar rates. In (C), an acute insult leads to the death of a subset of ganglion cells: the other ganglion cells then die because of secondary degeneration rather than because of a defined insult, at variable rates.

A further possibility to consider is that only a single subset of ganglion cells is initiated to die in glaucoma and that the other ganglion cells subsequently die in response to their death-that is, the concept of secondary degeneration (Fig 1C). ${ }^{16}{ }^{17}$ It is necessary here to understand not only why only some ganglion cells are initiated to die but also to determine the events that lead to the death of the remaining ganglion cells. No evidence exists to suggest that inflammation is associated with glaucoma, and ganglion cells are thought to die by apoptosis (see below). It seems unlikely, therefore, that factors

Table 2 Some possibilities that may account for the variability of the death rate of ganglion cells in glaucoma

- Variability of types of ionotropic glutamate receptors associated with ganglion cells

- Variability of numbers of ionotropic glutamate receptors associated with different ganglion cells

- Variability of receptor types associated with ganglion cells (for example, nicotinic cholinergic, GABAergic, serotonergic, dopaminergic)

- Variability of natural protective mechanisms (for example, calcium binding proteins or chaperones) associated with different ganglion cells

- Variability of vascular supply to different ganglion cells

- Variability in damage to ganglion cell axons in optic disc area

- Susceptibility of ganglion cells associated with size of somata and/or axon diameter (for example, glutamate) are released from dying or dead ganglion cells to cause the death of the remaining ganglion cells.

DAMAGE TO GANGLION CELL AXONS

Excavation of the optic disc is a recognised clinical feature of glaucoma which may indicate that ganglion cells die because of an insult to their axons. Many theories exist to explain how axon function can be affected to trigger ganglion cell death in glaucoma. An alteration in the biochemistry, and hence function, of any of the many components in the optic nerve (lamina cribrosa, astrocytes, oligodendrocytes, microglia, blood capillaries) can indirectly affect normal ganglion cell axon function. Changes have been shown in the structure of the lamina cribrosa ${ }^{18}{ }^{19}$ and in the amount of cyclo-oxygenase ${ }^{20}$ transforming growth factor $\beta$ (TGF- $\beta),{ }^{21}$ nitric oxide synthase, ${ }^{22}$ and glycosaminoglycans, ${ }^{19}$ for example, in the optic nerve of glaucoma patients. However, it is difficult to know whether such changes in the glaucomatous optic nerve indicate cause or effect.

Experimental support for the idea that the site of injury of the ganglion cell in glaucoma is the axon was first produced by Anderson and Hendrikson ${ }^{23}$ on an acute monkey model of glaucoma. Using radioactive probes they demonstrated blockage of axonal transport in the ganglion cells at the level of the sclera in the optic nerve head. Subsequent studies pinpointed the site of injury in the optic nerve to the collagenous tissue beams opposite the sclera. ${ }^{2425}$ The abnormality was reversible with normalisation of pressure in the experimental model. ${ }^{7}$ While these findings may be of relevance to glaucoma it is also important to bear in mind that the effect on ganglion cell axons in the animal model is the result of elevated pressure and that not all glaucoma patients have raised pressure. In fact, as much as a third of all glaucoma patients are estimated not to have abnormal intraocular pressures ${ }^{26}{ }^{27}$ - that is, intraocular pressures of $21 \mathrm{~mm} \mathrm{Hg}$ or less. However, abnormalities in the collagenous connective tissue beams opposite the sclera have been described in human eyes with glaucoma. ${ }^{28}$

The vascular supply to the optic nerve head and the optic nerve is complex ${ }^{29}$ and any malfunction may cause ischaemic/hypoxic-like insults to the ganglion cell axons. There is some evidence to support the view that the blood supply to the optic nerve head is altered in glaucoma patients. ${ }^{30}$ Ganglion cell axons and surrounding glial elements are dependent on the local blood supply for their energy requirements. Raised pressure may result in an alteration of the blood supply to the optic nerve head to induce ischaemia/hypoxia and this in turn may affect normal ganglion cell axon function. Thus, it is possible that in the acute monkey model for glaucoma (described above) the blockage of ganglion cell axonal transport mechanisms is due to ischaemia/hypoxia.

\section{INSUFFICIENT TROPHIC FACTOR(s)}

Axonal injury is known to result in retrograde neuronal degeneration. In the cat retina, $40-45 \%$ of the ganglion cells degenerate and die within 1 week of optic nerve section. ${ }^{31}$ A common explanation for neuron degeneration after axotomy is that the cell body is deprived of a growth factor that it receives from the target field. ${ }^{32}$ Consistent with this idea is the finding that ganglion cell degeneration can be partially prevented by intravitreal administration of large doses of growth factors such as fibroblast growth factors, ${ }^{33}$ nerve growth factor, ${ }^{34}$ ciliary neurotrophic factor, ${ }^{35}$ and brain derived neurotrophic growth factor (BDNF). ${ }^{36}$ Since axons within rat optic nerve show a capacity for regrowth following transection, ${ }^{37-39}$ and certain 




Figure 2 Immunohistochemical staining showing the presence of brain derived neurotrophic growth factor (BDNF) $(A)$ and the TrkB receptor (B) in the retina. Clearly the immunofluorescence is associated with the ganglion cells in each case.

growth factors promote this growth and survival, ${ }^{40}$ the suggestion has been made that ganglion cells die in glaucoma because of a lack of specific growth factors. BDNF has been particularly discussed in this respect because this neurotrophin and its high affinity receptor, TrkB are associated with ganglion cells (Fig 2). Moreover BDNF, is known to be transported by CNS neurons ${ }^{41}$ and when $\mathrm{BDNF}$ is injected into the superior colliculus it reduces developmental ganglion cell death. ${ }^{42}$

It has been mooted that in glaucoma there is damage to the optic nerve and the retrograde transport of BDNF from the brain to the ganglion cell somata for normal survival is altered resulting in ganglion cell death. Recent experiments have shown BDNF transport in the optic nerve head to be altered in an experimental glaucoma monkey and after acute IOP elevation in rats, ${ }^{8}$ which supports such a hypothesis.

A decrease in retinal BDNF activity may also arise for reasons that are independent of damage to the optic nerve and this could theoretically participate in ganglion cell death. It is known that intravitreal injection of BDNF reduces ganglion cell degeneration. ${ }^{36}$ It has, however, also been reported that ganglion cell numbers are unaffected in knockout mice lacking $\mathrm{BDNF},{ }^{43}$ suggesting that a decrease in the BDNF activity in a healthy retina has little effect on ganglion cell survival.

OVEREXCITEMENT OF THE GANGLION CELLS

The types of receptors associated with ganglion cells may be the most important reason to explain not only why 


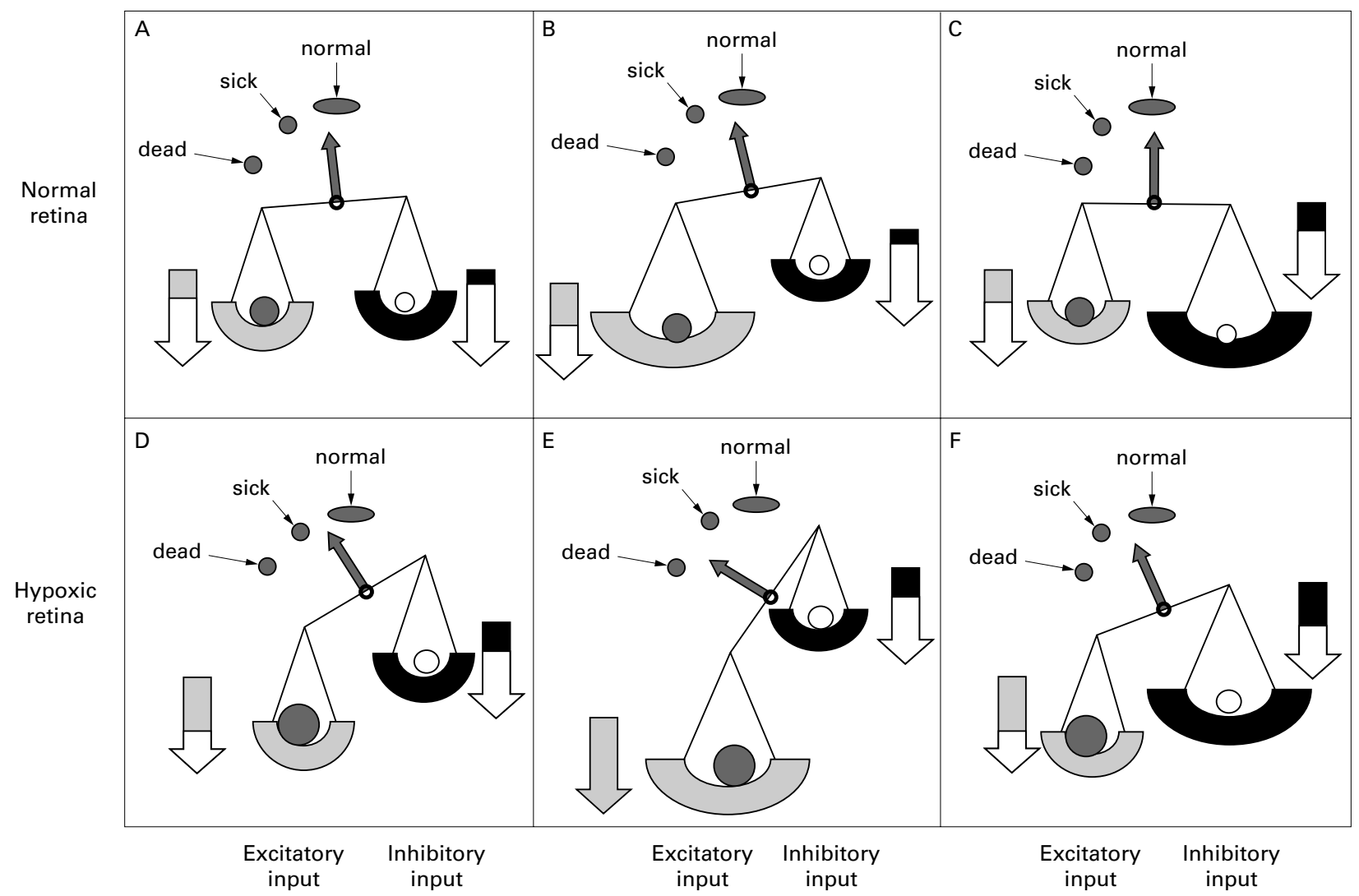

Figure 3 A schematic representation of how ganglion cells may die by overexcitation as would occur in hypoxia/ischaemia. In the normal healthy retina $(A-C)$ the degree of excitation of a ganglion cell will be a balance between the level of excitatory and inhibitory neurotransmitters (solid and open circles, respectively) and the complement of excitatory (for example, ionotropic glutamate) and inhibitory (for example, GAB $A_{A}$ ) receptors (grey and black buckets, respectively). The degree of stimulation will depend on the complement of receptors. However, the cells are not overstimulated whether they have the equivalent number of excitatory and inhibitory $(A)$, more excitatory $(B)$, or more inhibitory $(C)$ receptors, because the level of neurotransmitters are at a low and controlled level. In hypoxialischaemia $(D-F)$, extracellular neurotransmitters are elevated and the potential for overstimulation of receptors can occur. Cells that contain equivalent numbers of excitatory and inhibitory receptors can become slightly overexcited (that is, suffer slightly more excitatory than inhibitory input than normal) and may therefore become sick or unhealthy (D). In contrast, cells that have very much more excitatory than inhibitory receptors (E) will be overstimulated to a greater extent and this could lead to immediate death. Theoretically, neurons that have more inhibitory than excitatory receptors will not be overexcited in hypoxialischaemia $(F)$ and are therefore less likely to suffer from the insult.

ganglion cells die in glaucoma but also why they die at different rates. Neurons contain excitatory and inhibitory receptors and under normal physiological conditions neither of these receptor types can be overstimulated because of appropriate homeostatic mechanisms. However, should overstimulation occur, as in ischaemia/hypoxia ${ }^{15}$ where all the receptors of a neuron are overexcited, then the susceptibility of the cell will depend on the combined effects of the receptors (Fig 3). If the combined effects greatly overexcite the neuron, then the cell will die. However, if the combined effects do not lead to overexcitement death is unlikely.

Excitatory ionotropic glutamate receptors are particularly abundant in the retina and are heavily associated with ganglion cells. ${ }^{44}$ Glutamate levels are elevated in the vitreous humour of glaucoma patients ${ }^{45}$ and ganglion cells are particularly susceptible to glutamate toxicity. ${ }^{15}{ }^{46} 47$ Moreover, glutamate is known to be released from retinal cells during hypoxia. ${ }^{48}$ All this information together suggests that the death of ganglion cells in glaucoma is because of overactivation of ionotropic (NMDA and kainate/AMPA) glutamate receptors and that hypoxia causes extracellular glutamate to rise. ${ }^{15}$ The idea that hypoxia/ischaemia plays a part in triggering glaucoma has been repeatedly enunciated $^{15}{ }^{47}$ even though definitive proof remains elusive.

The destructive effect of glutamate on ganglion cells is primarily due to its interaction with ionotropic glutamate receptors. Overstimulation of these ionotropic glutamate receptors results in a large influx of calcium to induce a death process. ${ }^{15}$ Thus, cells which express specific types and levels of ionotropic glutamate receptors may vary in susceptibility and die at different times. In addition, certain receptor types, including nicotinic cholinergic, GABAergic, dopaminergic, and serotonergic, are known to be associated with certain populations of ganglion cells. Activation of these receptors may play a part in stimulating or reducing the rate of ganglion cell death induced by glutamate.

When nerve cells are subjected to ischaemia, a reduction in the membrane ATP level occurs and this leads to equilibration between intracellular and extracellular components. ${ }^{49} 50$ Thus, there will be an increase of all "neurotransmitters" in the extracellular medium. In hypoxia, this will be less pronounced although the nerve function will be affected by the "released" neurotransmitters. In ischaemia, this will only occur during reperfusion when ATP can again be generated. When the inner retina is subjected to hypoxia, as appears to be the case in glaucoma, ${ }^{15}$ then the combined effects of "released" neurotransmitters from all retinal cells on ganglion cells will determine the rate at which that ganglion cell will die. If the combined effects of the neurotransmitters result in the overactivation of a cell then the death process will be initiated. It is therefore possible that the variable complement of receptor types associated with different ganglion cells is the reason why all ganglion cells do not die at the same time in glaucoma. If this is confirmed then such information will be essential for the future development of suitable neuroprotectants for use in glaucoma. 
Stimulation of nicotinic acetylcholine receptors (nAChRs) leads to an influx of calcium into neurons ${ }^{51}$ and these receptors are known to be associated with some ganglion cells. ${ }^{52}$ Since all neurotransmitters are released in excessive amounts in hypoxia, a ganglion cell that contains both nAChRs and NMDA receptors will theoretically be more susceptible to death than a cell that contains only NMDA receptors. Conversely, activation of receptors which results in an influx of an anion such as chloride, as in the case of the $\mathrm{GABA}_{\mathrm{A}}$ receptor, will tend to counteract the detrimental effects of an influx of calcium caused by activation of NMDA receptors. Thus a ganglion cell which contains both inhibitory $\mathrm{GABA}_{\mathrm{A}}$ and excitatory NMDA receptors is theoretically less likely to be damaged than a cell which contains only NMDA receptors.

Before concluding this section it must be emphasised that persuasive evidence exists to support the view that at least some of the characteristic arcuate visual field loss in glaucoma could well be the result of changes at the level of the optic disc caused by pressure. Burgoyne's recent work on stress changes at the level of the optic nerve head is worth mentioning in this respect. ${ }^{53}$ Thus, the cause of the selective death of ganglion cells in glaucoma may ultimately prove to be a combination of factors, which might include differences in the receptor complement of individual ganglion cells.

\section{Elevated glutamate in the vitreous humour of glaucoma patients: significance}

The finding that the glutamate level in the vitreous humour of glaucoma patients is raised ${ }^{45}$ is of potential significance and discussed in detail elsewhere. ${ }^{15}$ The noteworthy issues are that our present knowledge on the subject is restricted to a single study and that the elevated glutamate could have originated from ischaemia, a malfunction in the way Müller cells metabolise glutamate, and/or a malfunction in the inactivation of released glutamate by two active transport processes. Another possibility which has been considered is that the glutamate originates from dead ganglion cells. ${ }^{45}$ We favour the view that the glutamate originates from hypoxia because in this state the efficient active transport process of extracellular glutamate into retinal cells will not function optimally. Moreover, glutamate and other neurotransmitters are likely to be released in excessive amounts from retinal neurons. As a consequence, neurotransmitters will accumulate and diffuse into the vitreous humour. Interestingly, of the amino acids analysed in the vitreous humour of glaucoma patients the two that were elevated were the neurotransmitters glutamate and glycine, but only the elevated glutamate level was determined as being significantly different from controls. ${ }^{45}$ The raised extracellular neurotransmitters will also activate receptors associated with defined neurons for which they are the natural ligands. It is postulated that the combined effects of the extracellular neurotransmitters on a neuron will result in death if excessive overexcitement occurs. Neurons that contain glutamate ionotropic receptors (ganglion cells) will be particularly susceptible to this effect because activation of such receptors results in depolarisation of the cell membrane.

\section{How good is the evidence for ganglion cells dying by apoptosis in glaucoma?}

No evidence exists to suggest that ganglion cells die in true or experimental glaucoma by necrosis, a death process traditionally associated with ischaemia. ${ }^{54}$ Necrosis is characterised by a compromised membrane integrity caused by ATP energy depletion; swelling eventually occurs and the mitochondria become dysfunctional. Eventually, the cell lyses and lysosomal enzymes are released into the extracel-
Table 3 Factors thought to differentiate between necrosis and apoptosis

\begin{tabular}{ll}
\hline Necrosis & Apoptosis \\
\hline - Occurs in groups of cells & - Occurs in isolated cells \\
- Gene expression not a & - Genetically controlled \\
prerequisite & - Precise internucleosomal cleavage of \\
- Late stage random DNA & DNA \\
cleavage & - No inflammation \\
- Inflammatory response & - Phagocytosis of apoptotic bodies by \\
- Phagocytosis of debris by & tissue cells and/or macrophages \\
macrophages & \\
\hline
\end{tabular}

lular space. Changes in the nucleus of a necrotic cell appear relatively unremarkable, at least during the early stage, but there is some swelling associated with the nuclear membrane followed by a scattering of materials into small masses. ${ }^{55}$ Another characteristic type of death process has been termed "apoptosis". This has been described as a process which requires energy and is characterised by clearly distinguishable changes in the nucleus but not in the cytoplasmic organelles, at least in the initial stages. ${ }^{5657}$ Cytoplasmic structures degenerate subsequently, and both the nucleus and the cytoplasm may form membrane bound "apoptotic bodies". Tissue macrophages ingest apoptotic bodies and dead cells thereby causing little or no inflammation. ${ }^{58}$ Table 3 illustrates some characteristic differences thought to differentiate apoptosis from necrosis.

There is, however, a problem in determining how a cell may have died in histological sections of pathological tissues. Membrane damage combined with an absence of a pyknotic nucleus are the main criteria for indicating necrosis. A pyknotic nucleus has been used as a marker for apoptosis ${ }^{59}$ because it suggests breakdown of DNA. A better way of revealing nucleosomal degradation as predicted to occur in apoptosis is by the TUNEL method ${ }^{60}$ although this method is not fully reliable ${ }^{61}$ In apoptosis, DNA fragments that are multiples of $\sim 180 \mathrm{bp}$ are generated and they can be detected by "staining" of the cell using a histochemical method (for example, TUNEL procedure) or by agarose gel electrophoresis ("ladder" technique). The fragments are produced by cleavage between the nucleosomes by $\mathrm{Ca}^{2+}$ activated endonucleases. In necrosis, non-specific degradation of DNA into randomly sized fragments occurs and these are not readily detected by the TUNEL method. Moreover, gradual cell shrinkage as reported by Weber et $a l^{12}$ appears not to be a unique feature of apoptosis.

It has not been easy to ascribe one specific form of cell death to a given situation in most pathological tissue sections. Accordingly, various authors have described cell death as occurring by "secondary necrosis", "intercurrent apoptosis and necrosis", "sequential apoptosis/necrosis", or "necrosis supervented over apoptosis". ${ }^{62}$ It is possible that in reality apoptosis and necrosis form a continuum at the extremes of a biochemically overlapping death pathway rather than being totally separate modes of death with only limited molecular and cellular biological overlap. ${ }^{62}$ Support for such a view comes from other studies which have shown that raised internal calcium and reactive oxygen species play major roles in both necrosis and apoptosis.

The basis for suggesting that ganglion cell death in glaucoma is by apoptosis is not because of any conclusive evidence but more because of a lack of any firm demonstration of cell necrosis. Similar conclusions have been reached after analysis of nervous tissues from most other pathologies (Alzheimer's disease, HIV infection, Huntington's disease, multiple sclerosis, trauma, etc) where there is no involvement of focal ischaemia. Since the rate of glaucomatous damage is very slow, it is hypothesised that very few cells would be expected to be found actually dying from 
apoptosis by the present techniques. In support of this, recent studies have indeed shown that although the number of TUNEL positive ganglion cells in glaucomatous patients is few, it is nevertheless greater than in control retinas. ${ }^{63}{ }^{64}$ Recent studies have also shown that immunoreactivity for the inflammation associated enzyme, cyclooxygenase-2, in the glaucomatous retina is unchanged compared with controls. ${ }^{20}$ This argues for an absence of inflammation, and endorses the idea that ganglion cell death in glaucoma is by apoptosis. However, the combined evidence for ganglion cells dying by apoptosis in glaucoma is not compelling as it is based primarily on TUNEL staining and histology. Since the TUNEL procedure can also in some cases detect breakdown of DNA by necrosis, ${ }^{61}$ the evidence is further weakened. It would therefore be unwise from present information to conclude that ganglion cells die solely by apoptosis in glaucoma. Moreover, cell death may be by mechanisms that remain to be discovered and which are applicable to glaucoma. As pointed out by Clarke $^{65}$ "the thesis that all neuron death is either apoptotic or necrotic is not universally valid, although it seems to be a good approximation in some instances".

\section{So what is really known about ganglion cell death in glaucoma?}

It is clear from the contents of this article that there remains a lack of definitive data as to why, how, and when ganglion cells die in true glaucoma. While some of our speculations and predictions stem from clinical observations, most come from data derived from animal studies. However, recognising the significance of data derived from animal models in relation to true glaucoma remains a problem. It is known that optic nerve crush, ocular ischaemia, and ocular hypertension will result in ganglion cell death ${ }^{1}$ but whether such data are of relevance, limited relevance, or of no relevance to true glaucoma cannot be judged with any degree of certainty. It could be argued that detailed answers to the questions posed about ganglion cell death in glaucoma can only be obtained by a series of studies on an animal model which precisely simulates true glaucoma. Unfortunately, we are a long way from achieving this goal. Realistic interpretation of data derived from studies on animal models may nevertheless yield data which, when viewed unbiasedly, may be of relevance to glaucoma, particularly in relation to the treatment of the disease.

The authors would like to thank the Sir Jules Thorne Charitable Trust and the TFC Frost Charitable Trust for their financial support. JM was supported by a Marie Curie fellowship (European Commission).

\section{NEVILLE N OSBORNE JOHN P M WOOD GLYN CHIDLOW JI-HONG BAE JOSÉ MELENA MARK S NASH}

Nuffield Laboratory of Ophthalmology, University of Oxford, Oxford OX2 6AW

Correspondence to: Professor Neville Osborne, Nuffield Laboratory of Ophthalmology, University of Oxford, Walton Street, Oxford OX2 6AW.

1 Osborne NN, Chidlow G, Nash MS, et al. The potential of neuroprotection in glaucoma treatment. Curr Opin Ophthalmol 1999;10:82-92.

2 Neufeld AH. New conceptual approaches for pharmacological neuroprotection in glaucomatous neuronal degeneration. F Glaucoma 1998;7:434-8.

3 Koroshetz WJ, Moskowitz M. Emerging treatments for stroke in humans. Trends Pharmacol Sci 1997;17:227-33.

4 Katz B, Wall M. The optic neuropathies. In: Slamovits TL, Burde R, eds. Neuro-ophthalmology. St Louis: Mosby, 1994:Section 2.

5 Rodieck RK, Brening RK. Retinal ganglion cells: properties, types, general Rodieck RK, Brening RK. Retinal ganglion cells: properties, types, general
pathways and transpecies comparison. Brain Behav Evol 1963;23:121-64. pathways and transpecies comparison. Brain Behav Evol 1963;23:121-64.
6 Smiddy WE, Green WR. Nutritional amblyopia: a histopathologic study with retrospective clinical correlation. Graefes Arch Ophthal 1987;225:321with 4 .
7 Quigley HA. Ganglion cell death in glaucoma: pathology recapitulates ontogeny. Aust NZ 7 Ophthalmol 1995;23:85-91.

8 Quigley HA. Neuronal death in glaucoma. Progr Retinal Eye Res 1998;18:39-57.

9 Glovinsky Y, Quigley HA, Pease ME. Foveal ganglion cell loss is size dependent in experimental glaucoma. Invest Ophthalmol Vis Sci 1993;34: 395-400.

10 Morgan JE. Selective cell death in glaucoma: does it really occur? $\mathrm{Br} f \mathrm{Oph}$ thalmol 1994;78:875-80.

11 Kalloniatis M, Harwerth RS, Smith EL, et al. Colour vision anomalies following experimental glaucoma in monkeys. Ophthalmic Physics Opt 1993;13:56-67.

12 Weber AJ, Kaufman L, Hubbard WC. Morphology of single ganglion cells in the glaucomatous primate retina. Invest Ophthalmol Vis Sci 1998;39:230420 .

13 Johnson CA. Selective versus nonselective losses in glaucoma. F Glaucoma (Suppl) 1994;3:532-4.

14 Graham S, Drance S, Chauhan B, et al. Comparison of psychophysical and electrophysiological testing in early glaucoma. Invest Ophthalmol Vis Sci 1997;37:497-503.

15 Osborne NN, Ugarte $M$, Chao $M$, et al. Neuroprotection in relation to retinal ischaemia and relevance to glaucoma. Surv Ophthalmol 1999; in press.

16 Yoles E, Schwartz M. Potential neuroprotective therapies for glaucomatous optic neuropathy. Surv Ophthalmol 1998;42:367-72.

17 Schwartz M, Belkin M, Yoles E, et al. Potential treatment modalities for glaucomatous neuropathy: neuroprotection and neuroregeneration. $f$ Glaucoma 1996;5:427-32.

18 Hernández MR, Andrzejewska WM, Neufeld AH. Changes in the extracellular matrix of the human optic nerve in primary open angle glaucoma. Am f Ophthalmol 1990;109:180-8.

19 Hernández MR, Pena JDO. The optic nerve head in glaucomatous optic neuropathy. Arch Ophthalmol 1997;115:389-95.

20 Neufeld A, Hernández M, González M, et al. Cyclooxygenase-1 and cyclooxygenase-2 in the human optic nerve head. Exp Eye Res 1997;65:739-45.

21 Pena JDO, Taylor AW, Ricard CS, et al. Transforming growth factor $\beta$ isoforms in human optic nerve heads. Br f Ophthalmol 1999;83:209-18.

22 Neufeld A, Hernandez M, Gozalez M. Nitric oxide synthase in human glaucomatous optic nerve head. Arch Ophthalmol 1997;115:497-503.

23 Anderson DR, Hendrickson A. Effect of intraocular pressure on rapid axonal transport in monkey optic nerve. Invest Ophthalmol 1974;13:77183

24 Quigley HA, Guy J, Anderson DR. Blockage of rapid axonal transport. Effect of intraocular pressure elevation in primate optic nerve. Arch Ophthalmol 1979;97:525-31.

25 Quigley HA, Addicks EM, Green WR, et al. Optic nerve damage in human glaucoma. II. The site of injury and susceptibility to damage. Arch Ophthalmol 1981;99:635-49.

26 Gupta N, Weinreb RN. New definitions of glaucoma. Curr Opin Ophthalmol 1997;8:38-41.

27 Douglas GR. Pathogenetic mechanisms of glaucoma are not related to intraocular pressure. Curr Opin Ophthalmol 1998;9:34-8.

28 Quigley HA, Dorman-Pease ME, Brown AE. Quantitative study of collagen and elastin of the optic nerve head and sclera in human and experimental monkey glaucoma. Curr Eye Res 1991;10:877-88.

29 Ernest JT. Optic disc blood flow. Trans Ophthalmol Soc UK 1976;96:348-51.

30 Flammer J, Orgül S. Optic nerve blood flow abnormalities in glaucoma. Progr Retinal Eye Res 1998;17:267-89.

31 Silveira LCL, Russelakis-Carneiro M, Perry VH. The ganglion cell response to optic nerve injury in the cat: differential responses revealed by neurofibrillar staining. F Neurocytol 1994;23:75-86.

32 Jacobson M. Developmental neurobiology. New York: Plenum Press, 1991.

33 Sievers J, Hausmann B, Unsicker K, et al. Fibroblast growth factors promote survival of rat retinal ganglion cells after transection of the optic nerve. Neurosci Lett 1987;76:157-62.

34 Carmignoto G, Maffei L, Candeo P, et al. Effect of NGF on the survival of rat retinal ganglion cells following optic nerve section. $\mathcal{F}$ Neurosci 1989;9:1763-72

35 Mey J, Thanos S. Intravitreal injections of neurotrophic factors support the survival of axotomized retinal ganglion cells in adult rats in vivo. Brain Res 1993;602:304-17.

36 Mansour-Robaey S, Clarke DB, Wang Y-C, et al. Effects of ocular injury and administration of brain-derived neurotrophic factor on survival and regrowth of axotomized retinal ganglion cells. Proc Natl Acad Sci USA 1994;91:1632-6.

37 Villegas-Pérez MP, Vidal-Sanz M, Bray GM, et al. Influences of peripheral nerve graft on the survival and regrowth of axotomized retinal ganglion cells in adult rats. $\mathcal{F}$ Neurosci $1988 ; 8: 265-80$.

38 Aguayo AJ, Rasminsky M, Bray GM. Degenerative and regenerative responses of injured neurons in the central nervous system of adult mammals. Phil Trans R Soc Lond Biol 1991;331:337-43.

39 Bray GM, Villegas-Pérez MP, Vidal-Sanz M, et al. Neuronal and nonneuronal influences of retinal ganglion cell survival, axonal regrowth, and connectivity after axotomy. Ann NY Acad Sci 1991;633:214-28.

40 Thanos S, Bähr M, Barde Y-A, et al. Survival and axonal elongation of adult rat retinal ganglion cells. Eur $\mathcal{F}$ Neurosci 1989;1:19-24.

41 Di Stefano PS, Friedman B, Radziejewski C, et al. The neurotrophins BDNF, NT-3 and NGF display distinct patterns of retrograde axonal transport in peripheral and central neurons. Neuron 1992;8:943-93.

$42 \mathrm{Ma}$ Y-T, Hsieh T, Forbes ME, et al. BDNF injected into the superior colliculus reduces development retinal ganglion cell death. $\mathcal{F}$ Neurosci 1998 ; 18:2097-107.

43 Cellerino A, Carroll P, Thoenen H, et al. Reduced size of retinal ganglion cell axons and hypomyelination in mice lacking brain derived neurotrophic factor. Mol Cell Neurosci 1997;9:397-408.

44 Brandstätter JH, Hartveit E, Sassoe Pognetto M, et al. Expression of NMDA and high-affinity kainate receptor subunit mRNAs in the adult rat retina. Eur 7 Neurosci 1994;6:1100-12.

45 Dreyer EB, Zurakowski D, Schumer RA, et al. Elevated glutamate levels in the vitreous body of humans and monkeys with glaucoma. Arch Ophthalmol 1996;114:299-305.

46 Siliprandi R, Canella R, Carmignoto G, et al. N-methyl-D-aspartateinduced neurotoxicity in the adult rat retina. Vis Neurosci 1992;8:567-73. 
47 Osborne NN. Neuroprotection in the retina: relevance to glaucoma. In: Drance SM, ed. Vascular risk factors and neuroprotection in glaucoma. Kregler Drance SM, ed. Vascular ris
Publications, 1997:139-56.

48 Neal MJ, Cunningham JR, Hutson PH, et al. Effects of ischaemia on neurotransmitter release from the isolated retina. F Neurochem 1994;62:1025-33.

49 Siesjo BK. Pathophysiology and treatment of focal cerebral ischaemia. Part II: mechanisms of damage and treatment. F. Neurosurg 1992;77:337-54

50 Siesjo BK. New perspectives in ischaemic brain damage? Progr Brain Res 1993;96:1-9.

51 Galzi JL, Changeux JP. Neuronal nicotinic receptors: molecular organization and regulations. Neuropharmacology 1995;34:563-82.

52 Lipton SA. Spontaneous release of acetylcholine affects the physiological nicotinic responses of rat retinal ganglion cells in culture. 7 Neurosci 1988 ; 8:3857-68.

53 Burgoyne CH. A biomechanical constituent for disc cupping. 1998 ARVO abstract No 1005:S219.

54 DeGirolami U, Zivin JA. Neuropathology of experimental spinal cord ischemia in the rabbit. $\mathcal{F}$ Neuropathol Exp Neurol 1992;41:129-49.

55 Wyllie AH, Beattie GJ, Hargreaves AD. Chromatin changes in apoptosis. Histochem $\mathcal{F}$ 1981;13:681-92.

56 Maino G, Joris I. Apoptosis, oncosis, and necrosis. An overview of cell death. Am f Pathol 1995;146:3-15.
57 Kroemer G, Petit P, Zamzami N, et al. The biochemistry of programmed cell death. Faseb f 1995;9:1277-87.

58 Wyllie $\mathrm{AH}$, Kerr JF, Currie AR Cell death: the significance of apoptosis. Int Rev Cytol 1980;68:251-306.

59 Russelakis-Carneiro M, Silveira LCL, Perry VH. Factors affecting the survival of cat retinal ganglion cells after optic nerve injury. $\mathcal{F}$ Neurocytol 1996; 25:393-402

60 Osborne NN, Cazevieille C, Pergande G, et al. Induction of apoptosis in cultured human retinal pigment epithelial cells is counteracted by flupirtine. Invest Ophthalmol Vis Sci 1997;38:1390-400.

61 Charriaut C, Ben-Ari Y. A cautionary note on the TUNEL stain to determine apoptosis. Neuroreport 1995;7:61-4

62 Raffray M, Cohen GM. Apoptosis and necrosis in toxicology: a continuum or distinct modes of death? Pharmacol Ther 1997;75:153-77.

63 Kerrigan LA, Zack DJ, Quigley HA, et al. TUNEL-positive ganglion cells in human primary open-angle glaucoma. Arch Ophthalmol 1997;115:1031-5.

64 Okisaka S, Murakami A, Mizukawa A, et al. Apoptosis in retinal ganglion cells increase in human glaucomatous eyes. fpn f Ophthalmol 1997;41:84-

65 Clarke PGH. Apoptosis versus necrosis. How valid a dichotomy for neurones? In: Koliatsos VE, Ratan RR, eds. Cell death and diseases of the nervous system. 1998:3-28. 